\title{
VISUALIZATION AND SIMULATION OF STRUCTURAL DYNAMICS OF NATURAL BROAD-LEAVED EVERGREEN FOREST AT XUAN SON NATIONAL PARK
}

\author{
Nguyen Tien Dung ${ }^{1,2}$ \\ ${ }^{1}$ Tay Bac University \\ ${ }^{2}$ Graduate University of Science and Technology, VAST
}

\begin{abstract}
ABSRACT
This research was conducted at Xuan Son National Park, the data was collected on three permanent plots and the area of each permanent plot is one ha. The data collection has been conducted in the period from 2012 to 2018 . The trees are classified into diameter categories of $5 \mathrm{~cm}$ starting from $10 \mathrm{~cm}$. The structural simulation model consists of two groups of system elements including: state elements (number of trees categorized by diameter size), intermediate elements (tree density, entering and outgoing tree number of diameter categories, number of died trees of different diameter categories, number of regenerating trees). The processes of forest dynamics (regeneration of trees, change of tree number and natural death of diameter categories) were simulated through a simulation scheme in MM\&S Software (Mathematical Modeling and Simulation - http://accountvienst.readyhosting.com/index.asp?prgID=1). The interaction is defined through regression equations: Correlation between the number of regenerating trees and the number of existing trees $\left(\mathrm{R}-\mathrm{N}_{0}\right)$, correlation between the number of diameter-category-changing trees and the number of trees at particular diameter category $\left(\mathrm{O}_{\mathrm{k}^{-}}\right.$ $\mathrm{N}_{\mathrm{k}}$ ), correlation between the numbers of died trees and trees at particular diameter category $\left(\mathrm{M}_{\mathrm{k}}-\mathrm{N}_{\mathrm{k}}\right)$. The suitable regression equations that are selected based on the results of statistic analysis were input into the model in the simulation diagram in MM\&S Software. The model in the simulation diagram has been ran, the graph was created from the results of model running to show the tendencies of the change of the tree diameter categories in time and to see the correlation between the changes of the tree diameter categories of the system. The model was exported from the simulation diagram into text file for illustration.
\end{abstract}

Keywords: Forest dynamics, structure, mortality, regeneration, MM\&S, Xuan Son.

Citation: Nguyen Tien Dung, 2018. Visualization and simulation of structural dynamics of natural broad-leaved evergreen forest at Xuan Son national park. Academia Journal of Biology, 40(4): 121-131. https://doi.org/10.15625/2615-9023/v40n4.13576.

*Corresponding author email: dungnt@utb.edu.vn

Received 16 June 2018, accepted December 2018

\section{INTRODUCTION}

Forest ecosystem is a very complex system consisting of animals, plants, microbes and other environmental elements, where the main element is the trees. These components have reciprocal interactions, affecting one another to maintain the existence of the ecosystem. Each element of the forest ecosystem constantly changes itself over time based on different ecological principles. Understanding such principles allows us to 
create solutions to manage the forest in a sustainable way.

Currently, the knowledge regarding the dynamics in the forest is still limited, especially regarding natural forest. The research using software and mathematical model to simulate the dynamics of the forest is essential and necessary for the management and sustainable use of forest resources. Visualization and simulation enable us to have a clear view, to estimate and forecast the dynamics of the forest. However, the research using software and mathematical model to simulate the dynamics of the forest yet remains few and far between.

Due to the aforementioned reasons, this research has been conducted with the purpose of finding out a few basic dynamics of forest in Xuan Son National Park, Phu Tho province. At the same time, the MM\&S software has been used to visualize and simulate the dynamics and structure of natural broad-leaved evergreen forest in order to create basis for sustainable forest management.

\section{MATERIALS AND METHODS}

The research was conducted at Xuan Son National Park in Phu Tho province, the data was collected on three permanent plots established since 2007 during the project "Research of the structural and dynamic characteristics of common forest types in Vietnam" (Tran Van Con, 2010).

Three square permanent plots have been established, the area of each plot is one ha. The data used in this article was collected from 2012 to 2018 . The trees are classified in diameter categories of $5 \mathrm{~cm}$ starting from $10 \mathrm{~cm}$. The collected data consists of: Diameter at $1.3 \mathrm{~m}\left(\mathrm{D}_{1.3}\right)$ of the trees that had $\mathrm{D}_{1.3}>10 \mathrm{~cm}$; Number of regenerating plants periodically added to tree group; Number of naturally died trees of each diameter category during the period of data collection.

The process of changing diameter category of the trees in the sample plots is calculated using the formula:

$$
\mathrm{N}_{\mathrm{k}, \mathrm{t}+1}=\mathrm{N}_{\mathrm{k}, \mathrm{t}}+\mathrm{R}_{\mathrm{k}}-\mathrm{O}_{\mathrm{k}}-\mathrm{M}_{\mathrm{k}}
$$

Where: $N_{k, t+1}$ is the number of trees with diameter of $\mathrm{k}$ diameter category at the time of $\mathrm{t}+1$;

$\mathrm{N}_{\mathrm{k}, \mathrm{t}}$ is the number of trees with diameter of $k$ diameter category at the time of $t$;

$\mathrm{R}_{\mathrm{k}}$ is the number of trees that are addingto the $\mathrm{k}$ diameter category;

$\mathrm{O}_{\mathrm{k}}$ is the number of trees that are outgoing from the $\mathrm{k}$ diameter category;

$\mathrm{M}_{\mathrm{k}}$ is the number of died trees of the $\mathrm{k}$ diameter category.

From the data collected at two different times, we can determine $\mathrm{N}_{\mathrm{k}, \mathrm{t}+1}, \mathrm{~N}_{\mathrm{k}, \mathrm{t}}, \mathrm{M}_{\mathrm{k}}$, and $\mathrm{R}_{\mathrm{k}}$ for the minimum diameter category $\left(\mathrm{R}_{\mathrm{k}}\right.$ is the number of regenerating plants added to this tree diameter category). From this, we can determine the number of outgoing trees from this diamter category using the formula:

$$
\mathrm{O}_{\mathrm{k}}=\mathrm{N}_{\mathrm{k}, \mathrm{t}}+\mathrm{R}_{\mathrm{k}}-\mathrm{M}_{\mathrm{k}}-\mathrm{N}_{\mathrm{k}, \mathrm{t}+1}
$$

SPSS software (Statistical Package for the Social Sciences) was used to select the suitable type of regression equation and to find the coefficients for each equation.

MM\&S Software (Nguyen Van Sinh, 2011) was used to visualize and simulate the dynamic processes and structure of the forest ecosystem.

\section{RESULTS AND DISCUSSION}

\section{Determining the system elements, description of models}

The goal of the models is to illustrate the dynamics and structure of Broad-Leaved 
Evergreen Forest Ecology at Xuan Son National Park in Phu Tho province. At one particular time, we could collect statistics on the number of trees classified by diameter category. Therefore, according to MM\&S software, the diameter category size would be the state element.

Density of the permanent plots $(\mathrm{N})$ is the total number of trees of different diameter categories that are depending on the number of trees of each diameter category at one time point. Therefore, density would be an intermediate element, according to $M M \& S$ software (Nguyen Van Sinh, 2011).

After a certain period of time from the growth in diameter, forest trees grew in width, some trees moved from the lower diameter category $\left(D_{k}\right)$ to a direct upper diameter category, this process is called diametercategory-change. The number of trees outgoing from the lower diameter category $\left(\mathrm{O}_{\mathrm{k}}\right.$ - Out $)$ would be added to the number of trees at the direct upper diameter category. It depends on the number of trees at the lower diameter category hence it is an intermediate element according to MM\&S software (Nguyen Van Sinh, 2011). It affects both the number of trees at lower diameter category and the number of trees at direct upper diameter category.

At each diameter category after a certain amount of time, there was a number of naturally died trees $\left(\mathrm{M}_{\mathrm{k}}-\right.$ Mortality) and the death rate at a diameter category depends on the tree number of the diameter category and is therefore an intermediate element, it affects the number of trees at that diameter category.

The first diameter category $(\mathrm{D}=10-15$ $\mathrm{cm}$, median $=12.5 \mathrm{~cm}$ ) after a certain amount of time received additional number of trees from the regenerating plants (R-Recruitment). On the other hand, the number of regenerating plants depends on the initial density of the sample plots, it is therefore an intermediate element according to MM\&S software (Nguyen Van Sinh, 2011). It influences the number of trees at the first diameter category.

Number of trees at each diameter category in the subsequent periods of time $\left(\mathrm{N}_{\mathrm{k}, t+1}\right)$ was the sum of the number of trees of last period $\left(\mathrm{N}_{\mathrm{k}, \mathrm{t}}\right)$, combined with the number of trees moving from the lower diameter category $\left(\mathrm{R}_{\mathrm{k}}\right)$, minus the number of trees outgoing from that diameter category $\left(\mathrm{O}_{\mathrm{k}}\right)$ and the number of died trees at that diameter category $\left(\mathrm{M}_{\mathrm{k}}\right)$.

\section{Simulation diagram}

Simulation diagram in MM\&S software was constructed based on the description of model.

The button $\square$ is used to draw the symbol of state variable. After clicking on this button, click on the simulation diagram window to enable the program to draw the symbol of state variable at the place of clicking.

The button is used to draw the symbol of intermediate variable. After clicking on this button, click at the simulation diagram window to enable the program to draw the symbol of intermediate variable at the place of clicking.

The button $(P$ is used to draw the link. After clicking at this button and clicking on a symbol of a state variable or an intermediate variable and drag the mouse to another state variable or intermediate variable, the program shall create link among those elements of the system.

Result of constructing the simulation is presented in Fig. 1.

After drawing, we let the MM\&S software inspect the completeness of the simulation diagram by clicking on the button $\sqrt{ }$ on the tool bar and we will get the message box informing the inspecting result, as presented in Fig. 2. 


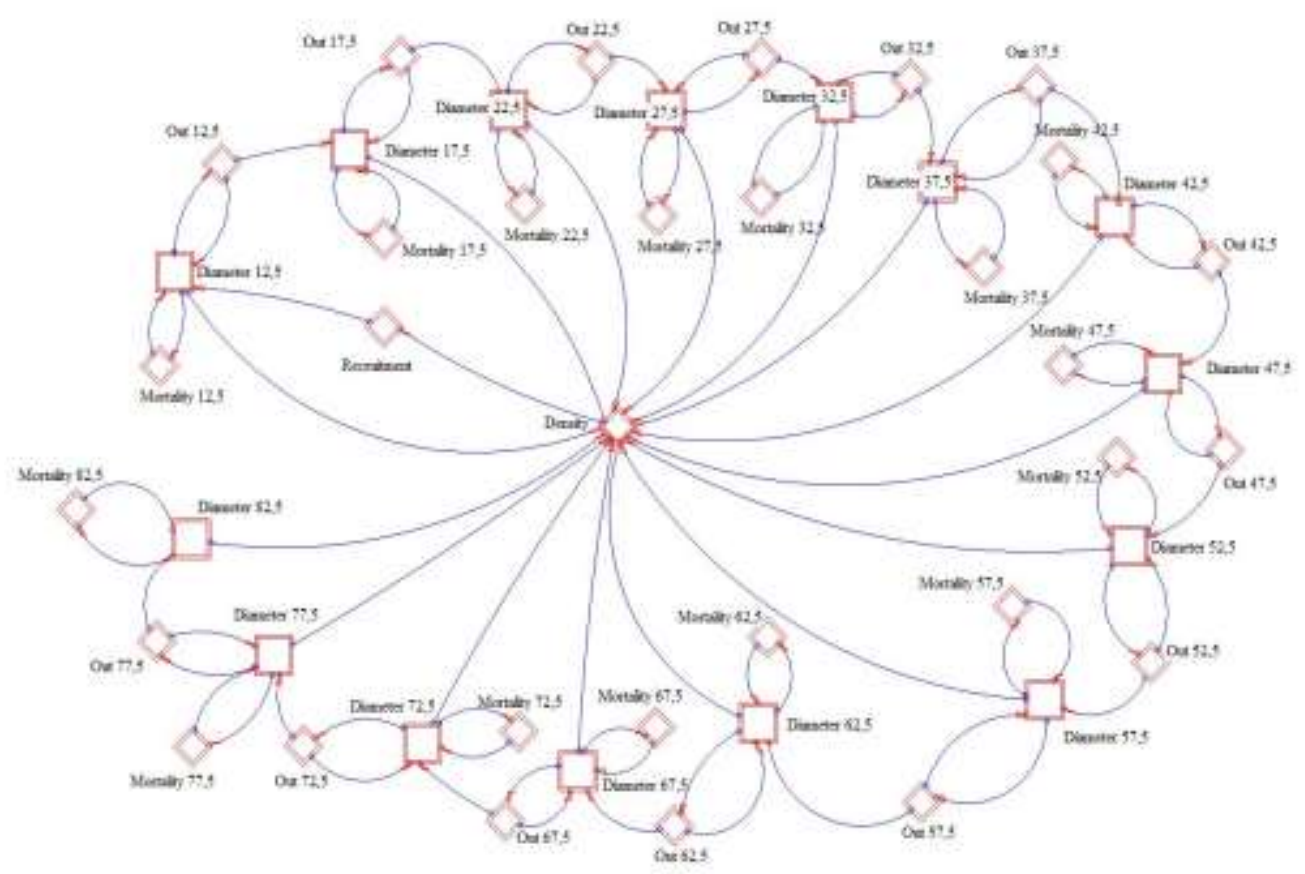

Figure 1. Diagram simulating the forest structure

\begin{tabular}{l} 
MM\&S - Results of simulation scheme checking \\
All the affecting variables are used \\
Did not find mistakes in simulation scheme \\
\hline
\end{tabular}

Figure 2. Result of inspecting the simulation diagram-simulation diagram is completed

When the MM\&S software announces: "All the affecting variables are used, did not find mistakes in simulation scheme" then the diagram was completed. Had the diagram not been completed, there would have been specific notices for each situation. Only when the simulation diagram was completed, the model can be ran from the diagram.

Quantifying the system elements and determining quantitative relation among the system elements

The elements in the system that needed to be quantifying: Number of regenerating plants, number of died trees at each diameter category and number of trees that change their diameter category.

In this research, the regeneration rate was calculated by the percentage of the original density. The calculation result showed that: $\mathrm{R}=0.05 * \mathrm{~N}_{0}$

Analyzing the relationship between the number of died trees $\left(\mathrm{M}_{\mathrm{k}}\right)$ and the total number of trees $\left(\mathrm{N}_{\mathrm{k}}\right)$ at each and the same diameter category we have:

Through the above table, we could see that there are 03 formulas suitable to describe this relationship: Linear $\left(\mathrm{R}^{2}=0,858\right)$, Quadratic $\left(\mathrm{R}^{2}=0,979\right)$ and Cubic $\left(\mathrm{R}^{2}=\right.$ 
0,984). However, the simulation result shown suitable to describe this relationship that Quadratic and Cubic formulas were really

(Fig. 3).

Table 1. Result of analysis of the relationship between $\mathrm{M}_{\mathrm{k}}-\mathrm{N}_{\mathrm{k}}$

\begin{tabular}{|c|c|c|c|c|c|c|c|c|c|}
\hline \multicolumn{10}{|c|}{ Model Summary and Parameter Estimates } \\
\hline \multicolumn{10}{|c|}{ Dependent Variable: Number of died trees } \\
\hline \multirow[t]{2}{*}{ Equation } & \multicolumn{5}{|c|}{ Model Summary } & \multicolumn{4}{|c|}{ Parameter Estimates } \\
\hline & R Square & $\mathrm{F}$ & df1 & df2 & Sig. & Constant & b1 & \begin{tabular}{|c|}
$\mathrm{b} 2$ \\
\end{tabular} & b3 \\
\hline Linear & .858 & 90.679 & 1 & 15 & .000 & -.109 & .033 & & \\
\hline Logarithmic & .495 & 14.718 & 1 & 15 & .002 & -2.815 & 1.534 & & \\
\hline Inverse & .153 & 2.712 & 1 & 15 & .120 & 3.191 & -9.928 & & \\
\hline Quadratic & .979 & 323.581 & 2 & 14 & .000 & .762 & -.006 & .000 & \\
\hline Cubic & .984 & 268.872 & 3 & 13 & .000 & .498 & .014 & $-3.977 \mathrm{E}-005$ & $3.551 \mathrm{E}-007$ \\
\hline Compound $^{\mathrm{a}}$ & . & 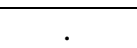 & . & . & . & . & . & & \\
\hline \multicolumn{10}{|c|}{ The independent variable is Number of trees at each diameter category } \\
\hline
\end{tabular}

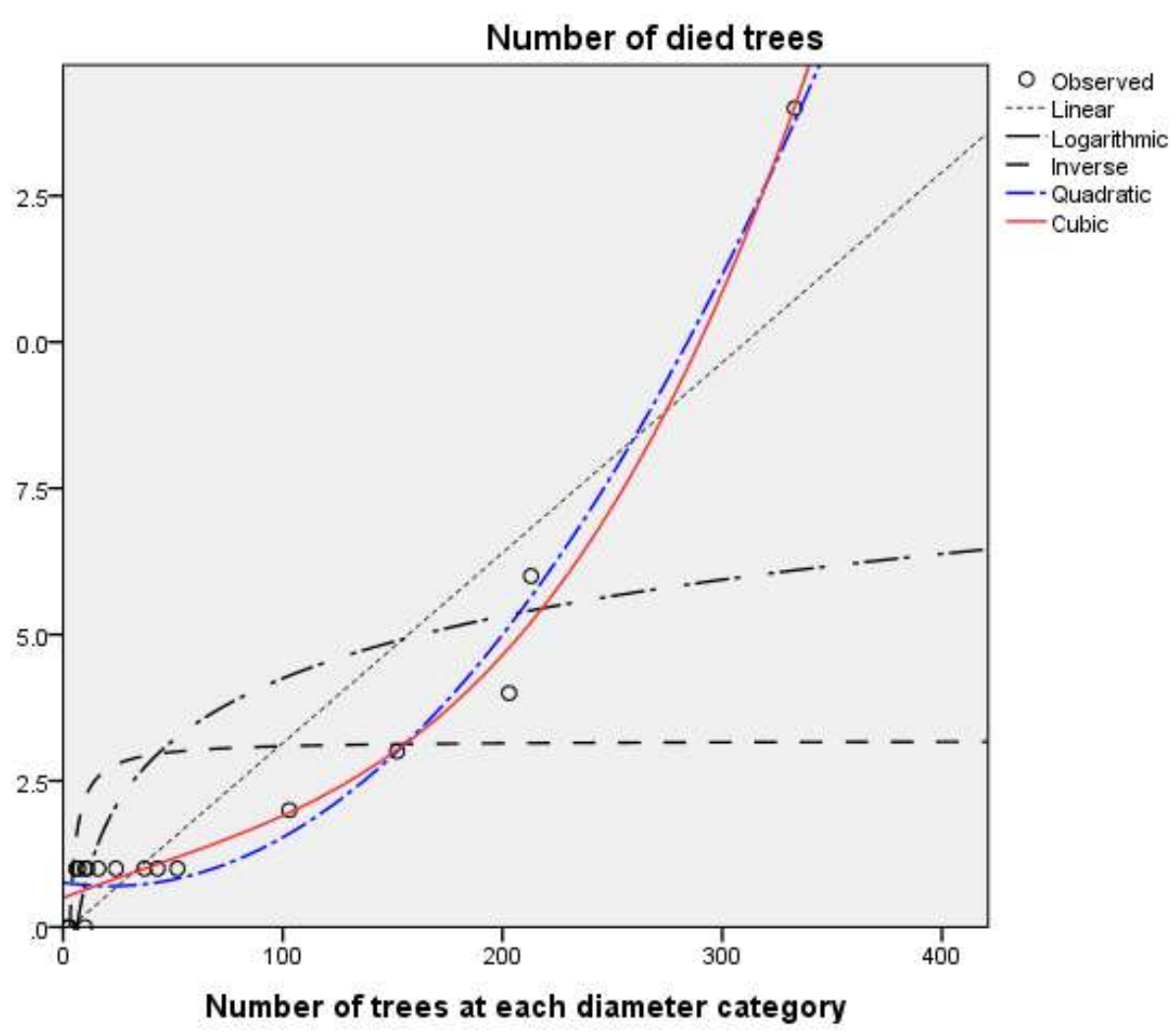

Figure 3. Result of simulation of the relationship between $\mathrm{M}_{\mathrm{k}}-\mathrm{N}_{\mathrm{k}}$

To simplify the calculation process, we choose Quadratic formula. Therefore, the relationship between $M_{k}$ and $N_{k}$ is represented by this equation:

$$
M_{k}=0.762-0.006 * N_{k}+0.0001345 * \mathrm{~N}_{k}^{2}
$$

This equation was used to calculate the number of died trees at each diameter category. 
Implemented the same steps to analyze the relationship between the number of trees that change their diameter category $\left(\mathrm{O}_{\mathrm{k}}\right)$ and the total number of trees $\left(\mathrm{N}_{\mathrm{k}}\right)$ at each and the same diameter category we received these results:

Table 2. Result of analyzing the relationship between $\mathrm{O}_{\mathrm{k}}$ and $\mathrm{N}_{\mathrm{k}}$

\begin{tabular}{|c|c|c|c|c|c|c|c|c|c|}
\hline \multicolumn{10}{|c|}{ Model Summary and Parameter Estimates } \\
\hline \multicolumn{10}{|c|}{ Dependent Variable: Number of trees changing their diameter category } \\
\hline \multirow[t]{2}{*}{ Equation } & \multicolumn{5}{|c|}{ Model Summary } & \multicolumn{4}{|c|}{ Parameter Estimates } \\
\hline & R Square & $\mathrm{F}$ & df1 & df2 & Sig. & Constant & 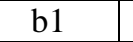 & b2 & b3 \\
\hline Linear & .984 & 934.969 & 1 & 15 & .000 & .778 & .245 & & \\
\hline Logarithmic & .747 & 44.320 & 1 & 15 & .000 & -25.160 & 13.240 & & \\
\hline Inverse & .249 & 4.983 & 1 & 15 & .041 & 26.978 & -88.995 & & \\
\hline Quadratic & .985 & 471.251 & 2 & 14 & .000 & 1.375 & .218 & $9.235 \mathrm{E}-005$ & \\
\hline Cubic & .991 & 474.952 & 3 & 13 & .000 & -.527 & .364 & -.001 & $2.560 \mathrm{E}-006$ \\
\hline \multirow{2}{*}{\multicolumn{10}{|c|}{ The independent variable is Number of trees at each diameter category }} \\
\hline & The inder & endent va & riable & is $\mathrm{NL}$ & ber of & trees at eac & i diameter & r category & \\
\hline
\end{tabular}

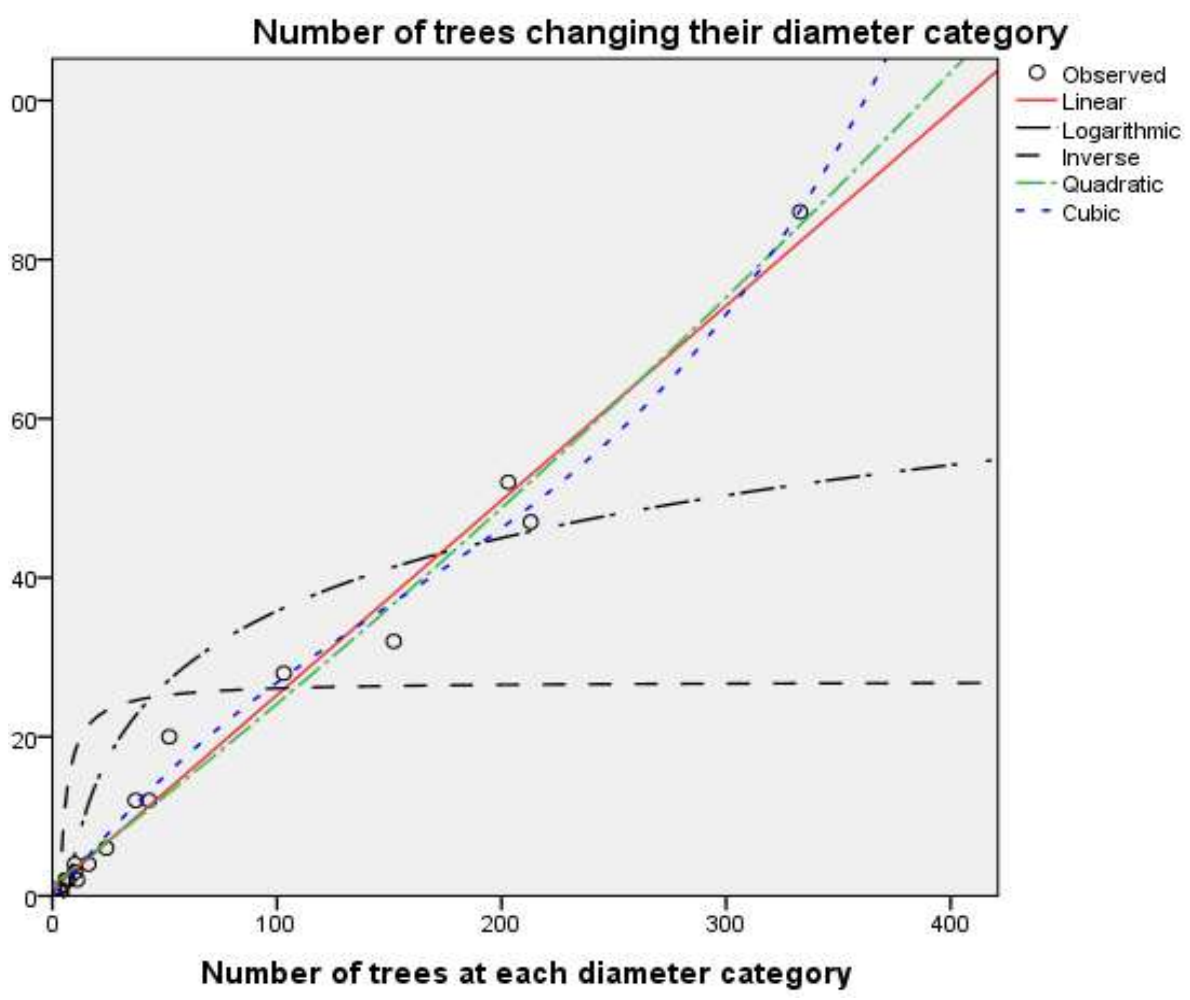

Figure 4. Result of simulation of the relationship between $\mathrm{O}_{\mathrm{k}}$ and $\mathrm{N}_{\mathrm{k}}$

Finally, linear formula was chosen to represent this relationship with the equation:

$$
\mathrm{O}_{\mathrm{k}}=0.778+0.245^{*} \mathrm{~N}_{\mathrm{k}}
$$

This equation was used to calculate the number of trees changing their diameter category at each diameter category. 
Inputting the model into the simulation diagram in MM\&S software

Double clicked at each symbol on the diagram, we proceeded to input information and formula for each element.

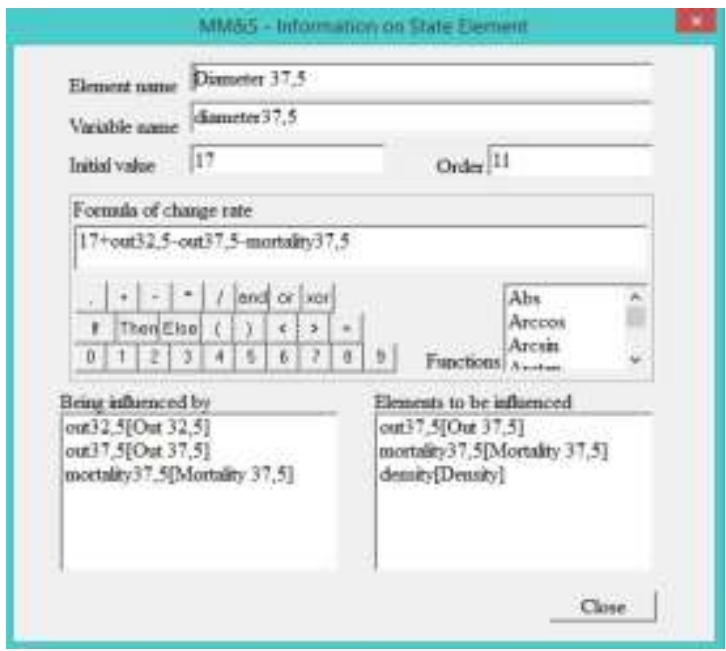

Figure 5. Text box for inputting information of state element

Information of the state element consists of: name of variable, start value, formula for calculating the change rate of state variable (based on the regression equation), elements that affect the state variable, the elements that are affected by the state variable (drawing simulation diagram will create these links).

\section{Export the model into text file}

After having completed the simulation diagram in $M M \& S$ software, in order to output the mo ${ }^{-1}-1$ into a text file we clicked at the button eX on the tool bar and the following text box will appear:

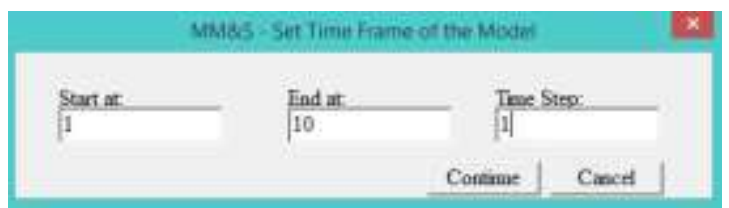

Figure 6. Set time frame of the model

Filled in the information of the start time, the end time, the time step, then click on the next button and we will receive a text file of the model:

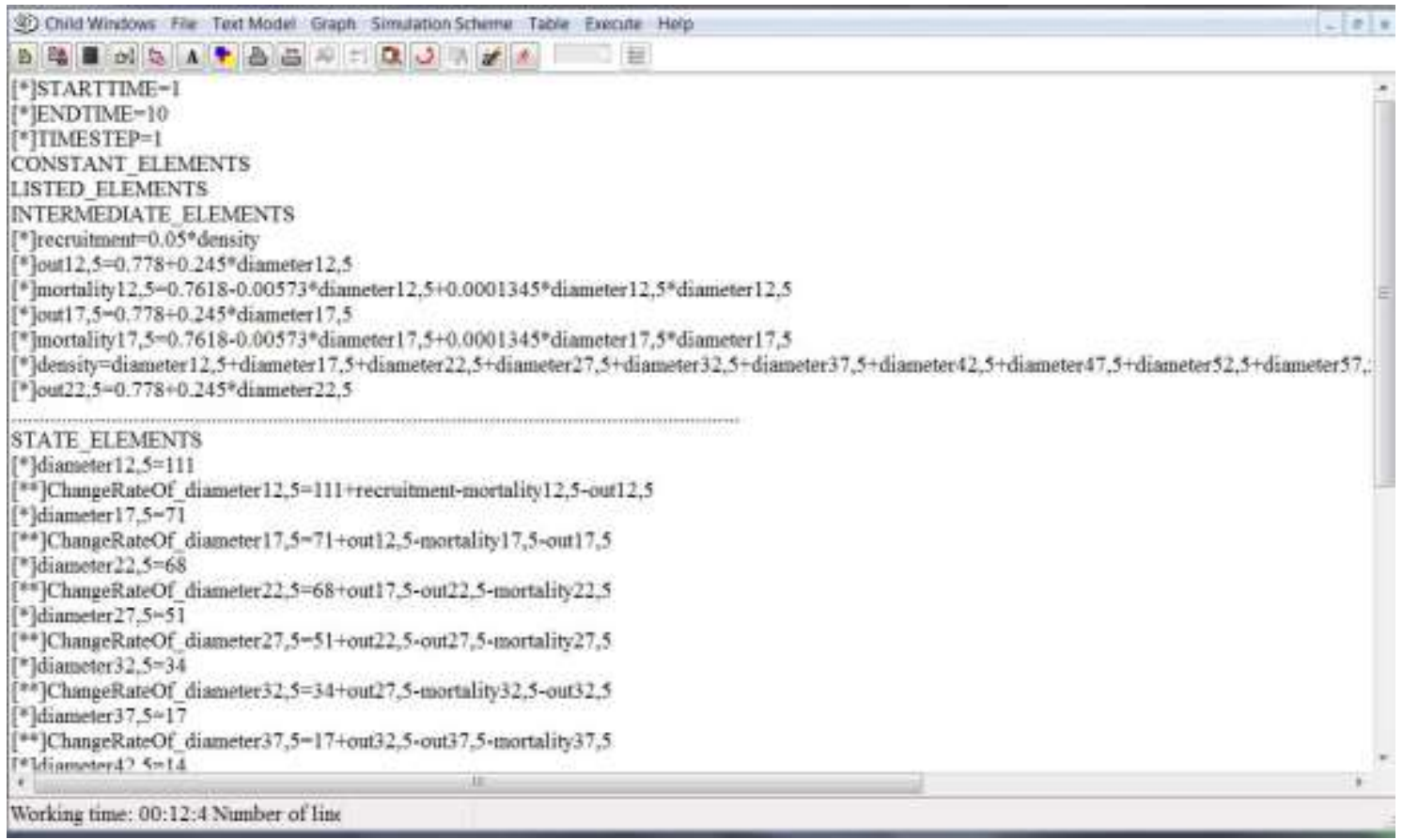

Figure 7. Model in text form 
Through the text form of the model, we got access to the information: the starting time, the ending time, the time step, the expression that calculate the number of regenerating plants, the number of died trees, the number of trees that changed their diameter category and change of tree number in each diameter category. Also through the text form of the model, we could recheck the related information in order to avoid mistakes during the process of constructing simulation model.

\section{Running model from simulation diagram}

In order to run the model, we clicked at the symbol $|\not x|$ on the tool bar of the simulation diagram child window of MM\&S, a dialogbox that determines the time frame will appear, input the time, press continue and we received the following result:

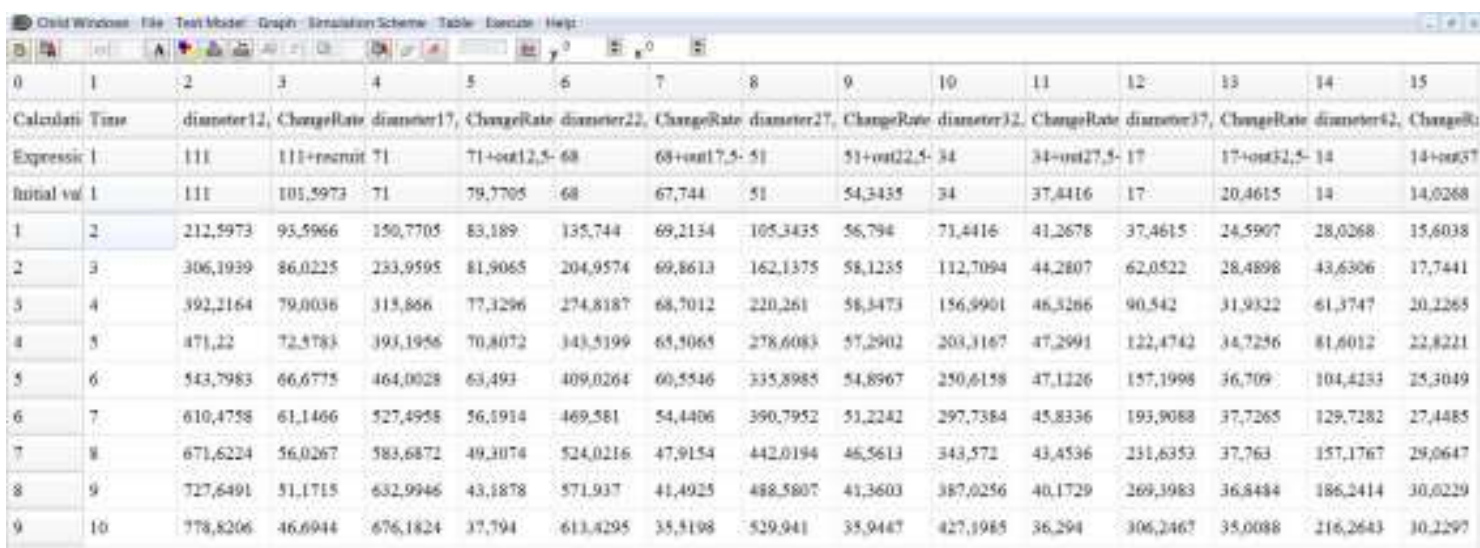

Figure 8. Result of running the model with the end time of 10 and calculation time step of 1

Through this table, we could see the tendency of change of the elements through time, and from there drew an overview regarding the dynamics of the system. The data was collected in a 6 years cycle, with calculation time step of 1 corresponding to the change of the forest in a 6 years cycle.

To better see the patterns in these changes, we proceeded to draw a graph to have an overview of them.

To draw a graph, we press the button on the tool bar of the MM\&S software and the following text box would appear:

In this dialogbox, we can select the variables to draw, the type of graph (time graph, phase graph, with or without sensitivity analysis), the scale (common or individual). The result is shown in Fig. 10.

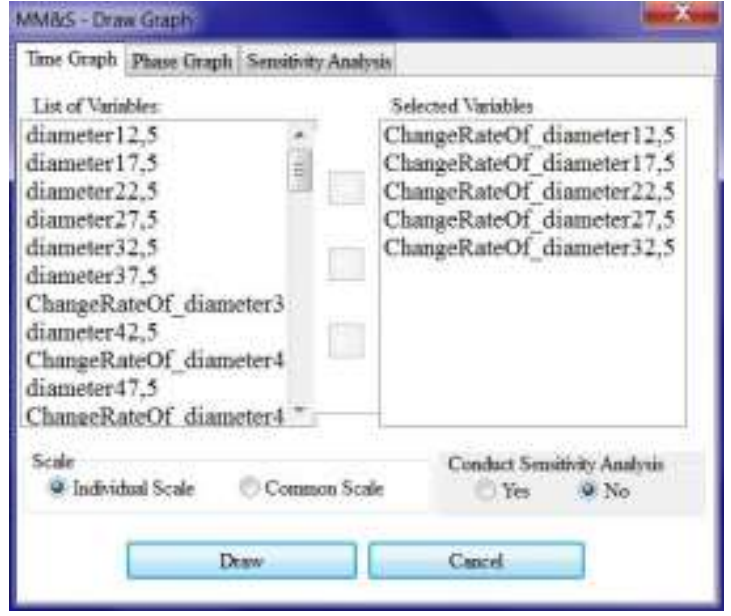

Figure 9. Dialogbox for selecting variables to draw a graph

Thus, after a cycle of 60 years (corresponding to the end time of 10) the diameter category $12.5 \mathrm{~cm}$ would have number of trees significantly reduced through time from 101 down to 46 trees. For the 
diameter categories from 17.5 to $27.5 \mathrm{~cm}$, the same change pattern happened but the speed of reduction gradually declined as the diameter size went up. For the diameter category of $32.5 \mathrm{~cm}$, the amount of change in the number of trees gradually increased until the middle of the cycle (calculation stage \#5) and then gradually declined in the subsequent stages. At larger diameter sizes, the amount of change in number of trees had a tendency to increase through time, however the increasing rates were not high (just a few trees in each calculation step). Overall, the density of the forest sample area would decrease through time (the number of trees decreased significantly at small diameter sizes and increased slightly at large diameter sizes). The change in the number of trees at small diameter size clearly illustrated the pattern of decreasing the number of trees pursuant to age in forest ecology: When the forest ages, the density would decrease.
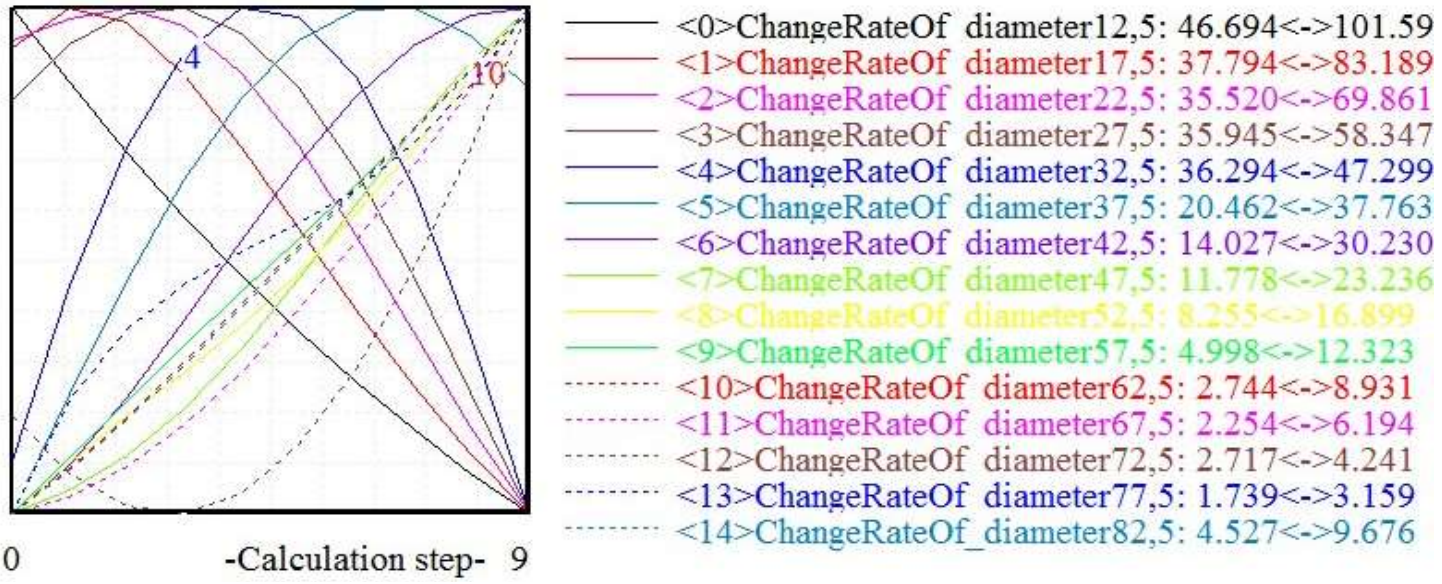

Figure 10. Time graph drawn for the variables of "ChangeRateof Diameter" with individual scale

The graphs for the variables "mortality" (number of died trees) of different diameter categories is presented in the Figure 11.
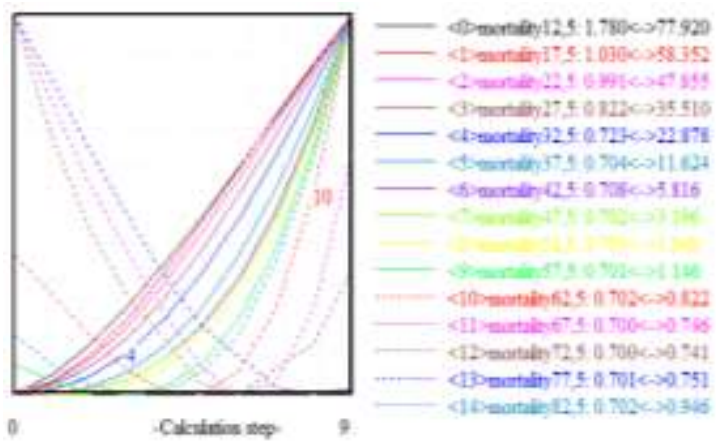

Figure 11. Time graph drawn for the variables of "mortality" (number of died trees) with individual scale

As evident from the graph in the figure 11, from diameter size $12.5 \mathrm{~cm}$ up to diameter size of $32.5 \mathrm{~cm}$, the number of died trees had the tendency to increase quickly and clearly through time. The strongest change happened at the smallest diameter size, and then gradually decreased as the diameter size increased. For the diameter size $>32.5 \mathrm{~cm}$, the change in number of died trees had the tendency to increase through time but the speed of increase was slow and insignificant (the change throughout the cycle was only a few trees).

Thus, we can use MM\&S software to efficiently simulate the structural dinamics of Natural Broad-Leaved Evergreen Forest at Xuan Son National Park. Through the simulation, we could easily visualize the relationship between the elements of the system through simulation diagram. To see clearly the quantitative relationships we shall use text form of the model which describes in 
full the relationships among the changes of the elements in the model, the way to determine the values of the elements in the model. Through the graph, we can clearly visualize the tendency of the changes of the elements in a particular period of time (time graph) and the correlation among the changes in values of two elements in the system (phase graph).

\section{CONCLUSION}

The model that illustrates the structural dynamics in accordance with the diameter size of Natural Broad-Leaved Evergreen Forest At Xuan Son National Park consists of following element groups: state elements (number of trees categorized by diameter size), intermediate elements (density, number of diameter-category-changing trees, number of died trees at different diameter categories, number of regenerating trees). These elements are related with each other, and their relationships are illustrated via the regression equations.

A model has been successfully constructed for simulating the structural dynamics of the forest in diagram form.

The dynamics in the forest have been analysed using mathematical statistics and suitable equations have been successfully selected for the simulation:

The process of regeneration: $\mathrm{R}=0.05^{*} \mathrm{~N}_{0}$

The process of dying of trees at different diameter categories:

$$
\mathrm{M}_{\mathrm{k}}=0.762-0.006 * \mathrm{~N}_{\mathrm{k}}+0.0001345 * \mathrm{~N}_{\mathrm{k}}{ }^{2}
$$

The process of changing diameter category of the trees: $\mathrm{O}_{\mathrm{k}}=0.778+0.245^{*} \mathrm{~N}_{\mathrm{k}}$

The simulation diagram has been completed with suitable equations. The model has also been exported into a text file for its better monitoring. The model has been running from the completed simulation diagram. Graphs have been drawn to see the tendency in the change of the elements through time as well as to notice the correlation between the changes of the elements of the system.

Within the calculation cycle (60 years) from diameter size of $12.5 \mathrm{~cm}$ to $27.5 \mathrm{~cm}$, the change in number of trees at each diameter category decreased, the speed of decrease gradually declined as the diameter size increased. At larger diameter size, the change in number of trees at each diameter category had the tendency to increase with time, but the amount of increase was not significant. Overall, the density of the forest sample area would decrease with time. The change in the number of trees at diameter categories illustrated clearly the pattern of decreasing the number of trees according to their age.

From diameter size of $12.5 \mathrm{~cm}$ to diameter size of $32.5 \mathrm{~cm}$, the change in number of died trees had the tendency to increase sharply and clearly with time. The strongest change happened at the smallest diameter size and gradually decreased as diameter size increased. For the diameter sizes $>32.5 \mathrm{~cm}$, the change in number of dead trees had the tendency to increase with time but the speed of the increase was slow and not significant.

\section{REFERENCES}

Do Thi Ngoc Anh, Nguyen Van Sinh, 2015. Modeling and simulation of ecologycal economic system of a household in the Khe Ro division of Tay Yen Tu nature reserve, Son Dong district, Bac Giang province, Viet Nam. Scientific reports on Ecology and Biological Resources, The $6^{\text {th }}$ National Scientific Conference on Ecology and Biological Resources, Ha Noi: 1227-1282.

Tran Van Con, 2010. Silvicultural research characteristics of forest ecosystems mainly in Vietnam, Report on Phase I of the project (2006-2010), Vietnamese Academy of Forest Sciences, Ha Noi. 
Nguyen Hung Manh, Nguyen Van Sinh, Nguyen Manh Hung, 2011. Modeling and simulation of a household economic system with pineplantation in the Huu San comune, Son Dong district, Bac Giang province. Scientific reports on Ecology and Biological Resources, The $4^{\text {th }}$ National Scientific Conference on Ecology and Biological Resources, $\mathrm{Ha}$ Noi: $1706-1712$.

Nguyen Van Sinh, 2011. Modeling dynamic systems with listed elements: new features of MM\&S software after the addition of table functions. Scientific reports on Ecology and Biological Resources, The $4^{\text {th }}$ National Scientific Conference on Ecology and Biological Resources, Ha Noi: $1778-1783$.

Nguyen Van Sinh, 2013. Analysis of the Lotka - Volterra model with MM\&S software. Scientific reports on Ecology and Biological Resources, The $5^{\text {th }}$ National Scientific Conference on Ecology and Biological Resources, $\mathrm{Ha}$ Noi: $1559-1567$.

Nguyen Hai Tuat, Nguyen Trong Binh, 2005. Exploiting and using SPSS to process research data in forestry, Agriculture Publishing House, Ha Noi.

Le Cong Vinh, Ha Thi My Ly, Nguyen Van Sinh, 2013. Application of MM\&S software in modelling and simulation of economic-ecological system of Thanh Xuan insect farm at 119 Tam Trinh - Mai Dong - Hoang Mai - Ha Noi and Hop village - My Phuc - My Loc - Nam Dinh province. Scientific reports on Ecology and Biological Resources, The $5^{\text {th }}$ National Scientific Conference on Ecology and Biological Resources, $\mathrm{Ha}$ Noi: 1723-1730. 
